\title{
Design of a Heat Exchanger Made of Gravity Heat Pipes with an Enlarged Heat Exchange Surface for Heat Dissipation from the Electrical Cabinet
}

\author{
Patrik Nemec ${ }^{1, *}$ \\ ${ }^{1}$ University of Zilina, Department of Power Energy, Univerzitná 8215/1, 01026 Zilina, Slovakia
}

\begin{abstract}
Due to the great progress in the electronics industry, heat management in electronic components is becoming a serious and important problem. Cooling of electronic components ensures a lower occurrence of failure of elements, longer service life of the device, protection against overheating of elements, further prevents malfunction of the device and loss of heat. In many cases, heat dissipation by natural convection is often insufficient. Heat dissipation by forced convection is effective, but it carries the risk of clogging the interior of the electrical cabinet with dust, which can negatively affect the functionality of the electrical elements over time. One of the possibilities of efficient heat dissipation from the electrical cabinet without forced convection is by means of heat pipe technology, which uses a phase change of the working substance for heat transfer. The article deals with the design, construction and experimental determination of the performance of gravity heat tubes with an increased heat exchange area suitable for the design of an electrical cabinet heat exchanger.
\end{abstract}

\section{Introduction}

The originator of the heat pipe is R. S. Gaugler, who in 1944 built a device with the primary purpose of heat transfer with the required power. It was a closed two-phase system with liquid and gaseous filling. Heat is transferred in the heat pipes through the phase change of the working medium state. The heat transfer medium evaporates in the evaporating part of the tube and the condensation of steam takes place in the condensing part of the tube, which actually transfers latent heat [1].

In 1962, Trefethen (1962) came up with the idea of using heat pipes in connection with the space program. The concept of the heat pipe attracted little attention until Grover (1964) published the results of independent research. Research in the field of phase change heat transfer has fully expanded worldwide in the 1970s and 1990s (especially in Russia, the USA, Japan and Europe). Research in this area continues to this day worldwide, as new

\footnotetext{
*Corresponding author: patrik.nemec@,fstroj.uniza.sk
} 
areas of application in terrestrial applications are increasingly being sought. At present, heat pipe technology is mostly associated with the cooling of electrical components [2].

The heat pipe consists of a sealed vessel lined with a capillary structure material. The vessel is vacuum sealed and filled with the correct volume of heat transfer medium. The work of the heat pipe is performed in a closed two-phase cycle, because there are only two phases in the vessel, namely pure liquid and steam. The working medium remains in the unsaturated state as long as the working temperature is between the triple point and the critical state. In Figure 1 is a heat pipe that is composed of three areas. Evaporation part, condensing part and adiabatic part. If heat is supplied to the evaporator section, the working medium heats up and begins to evaporate. The high temperature and pressure in this part create steam, which flows towards the condensing part, where it condenses and transfers latent heat. By capillary forces, the heat transfer medium then flows back into the evaporator part [3].

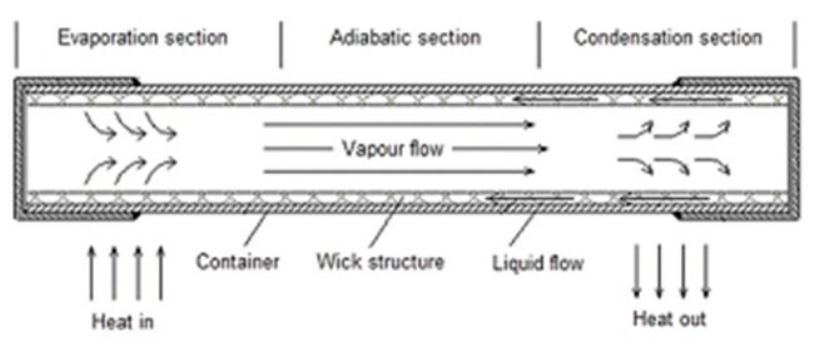

Fig. 1. Principle of heat pipe.

\section{Design of gravitational heat pipes with an increased heat exchange surface}

The thermal, temperature and hydraulic characteristics of gravitational heat pipes determine the properties of transfer phenomena during the evaporation and condensation of the heat transfer medium and the flow of gas and liquid phases in the heat pipe. These properties depend on the design of the heat pipes and at the same time on their technological design $[4,5]$.

The material for the production of a gravity heat pipe must meet several aspects. The strength must be high enough so that the internal dimensions or the internal pressure do not change under external or even internal loads.

The choice of material depends on the following aspects:

- good thermal conductivity,

- good machinability and weldability,

- compatibility with the working heat transfer medium and with the external environment,

- price, weight and strength ratio.

The compatibility between the working heat transfer medium and the heat pipe material is very essential for the correct functioning and achievement of the required service life parameters. Improper compatibility of the heat pipe material and the heat transfer medium can lead to corrosion or the formation of non-condensible gases, which causes a reduction heat pipe performance or its complete failure $[6,7]$.

A copper tube with a diameter of $\varnothing 12 \mathrm{~mm}$ with aluminium lamellas of circular crosssection on the outside with a diameter of $\varnothing 28 \mathrm{~mm}$ was used for the production of a gravity heat pipe with an increased heat exchange area shown in Figure 2. The length of the heat 
pipes is $210 \mathrm{~mm}$. The proposed length is due to its use for cooling the interior space in a particular type of electrical cabinet with power elements in which space is limited to placement a heat exchanger.

To compare the amount of thermal performance transferred by the heat pipe with the increased heat exchange area, gravity heat pipe without the increased heat exchange surface shown in Figure 3 was also made of a copper tube with a diameter of $\varnothing 12 \mathrm{~mm}$ and a length of $210 \mathrm{~mm}$.
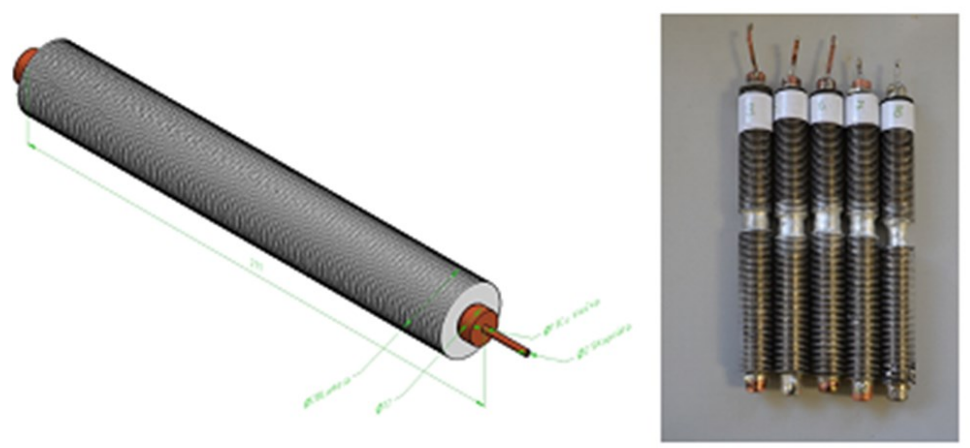

Fig. 2. Design gravitational heat pipe with increased heat transfer surface.
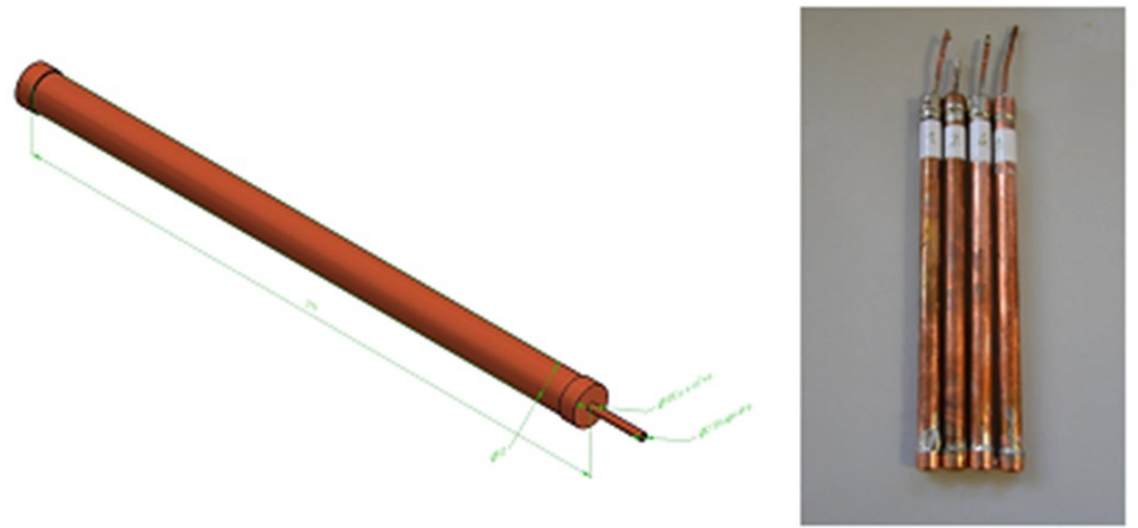

Fig. 3. Design gravitational heat pipe without increased heat transfer surface.

\section{Design of measuring equipment}

The experimental device was designed and constructed with regard to simplicity, reliability and safety in measuring the performance parameters of a gravitational heat pipe. The essence of determining the performance parameters lies on the basis of measuring the temperature difference of the inlet and outlet cooling and heating medium and measuring the flow of the cooling and heating circuit. The cooling circuit passes through the condensing part of the heat pipe and the heating circuit passes through the evaporating part of the heat pipe. The aim was to ensure the smallest possible adiabatic part that does not participate in heat exchange. By ingeniously constructing the experimental equipment, we 
managed to minimize the adiabatic part to $5 \mathrm{~mm}$ out of the total length of the heat pipes of $210 \mathrm{~mm}$.

In Figure 4 is the construction of the measuring device. This device is adapted to the dimensions of the designed heat pipes. It is possible to perform measurements of heat pipes without an increased heat exchange area as well as heat pipes with an increased heat exchange area. A great advantage of the measuring device is the possibility of quick exchange and fixing of heat pipes, as the measurement was performed on several heat pipes. The heating part of the device is separated from the cooling by thermal insulation in order to avoid mutual thermal influence. The whole construction of the experimental device was also covered with thermal insulation, so that during the measurement there would be no heat loss or gains.
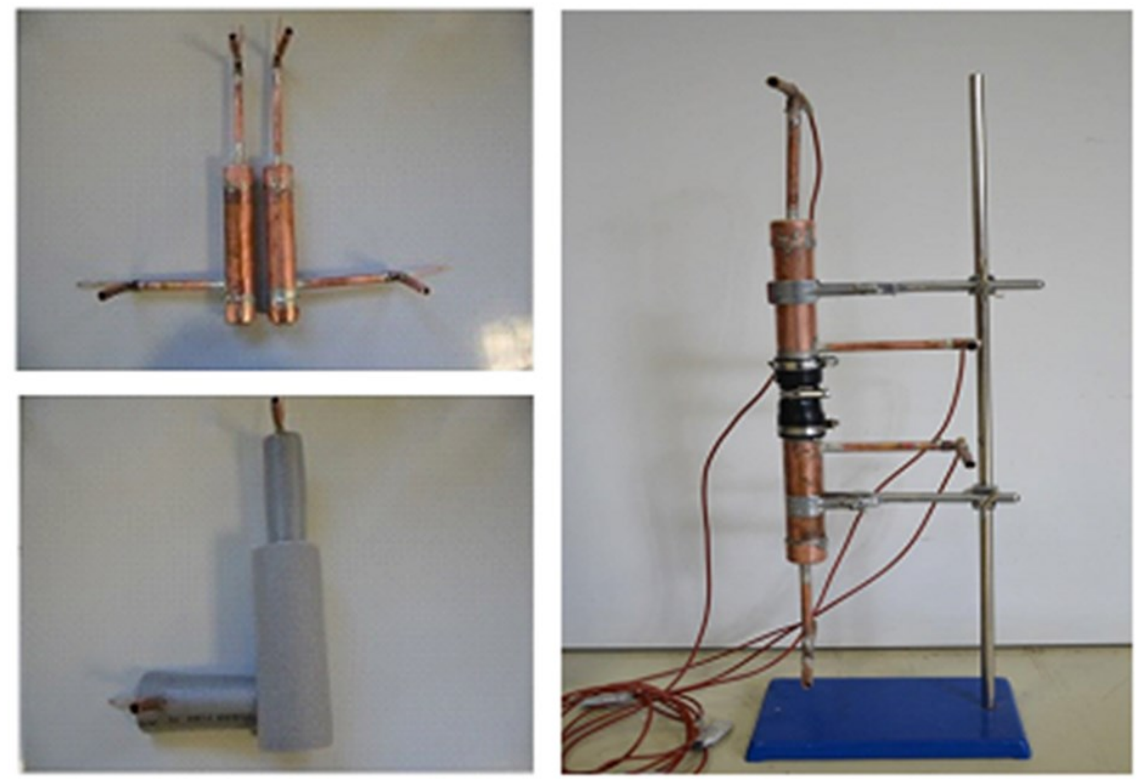

Fig. 4. Construction of measuring device.

\section{Measurement of performance parameters of a gravitational heat pipe}

The measurement of the performance parameters of the gravitational heat pipe was performed on an experimental measuring device in a vertical position. In Figure 5 is a Scheme of the whole experimental measuring rig.

An ultrasonic flow meter is connected to the output of the cooling thermostat, which measure the flow rate of the cooling medium. The cooling medium enters the lower part of the cooler, where the condensing part of the heat pipe is located. From the top of the cooler, the heated coolant goes back to the cooling thermostat. Temperature sensors are located at the inlet of the cooler and its outlet, which measure the change of the temperature of the cooling medium. Another thermometer is located in the cooling thermostat, which has a control function.

The same connection principle as for the cooling system is used for the heating system. The output of the heating thermostat is connected to an ultrasonic flow meter which measure the flow rate of the heating medium. The heating medium enters the lower part of 
the heater where the heat pipe is located and heats it. In the upper part of the heater heating medium exit and returns to the heating thermostat. At the inlet and outlet of the heating part of the experimental device there are also temperature sensors which measure the temperature difference of the entering and exiting medium.

All temperature and flow sensors were connected to the input of the measuring unit.

Measuring unit is used in experimental measurements for converting signal of measuring sensors $[8,9]$. For the accurate measurement in experimental measurements is necessary sensors calibration $[10,11,12]$. The output of the measuring unit is connected to a laptop, which wrote all measured values from the experimental device every $15 \mathrm{~s}$ via measuring software. The amount of thermal performance transferred by the gravitational heat pipe was determined by calculating a calorimetric equation, which is widely used in experiments solutions of heat transfer $[13,14,15]$.

$$
\begin{aligned}
& \bar{Q}=\dot{m} \cdot c_{p} \cdot \overline{\Delta t_{i}} \\
& \overline{\Delta t_{i}}=\overline{t_{v 2}}-\overline{t_{v 1}}
\end{aligned}
$$

Where $Q$ is thermal performance (W), $m$ is the mass flow rate of the refrigerant $\left(\mathrm{kg} . \mathrm{s}^{-1}\right)$, $c_{p}$ is the specific heat capacity of the heat transfer medium at constant pressure $\left(\mathrm{J} \cdot \mathrm{kg}^{-1} \cdot \mathrm{K}^{-1}\right)$, $\Delta t_{i}$ is the difference between the mean temperatures of the heat transfer medium at steady state $\left({ }^{\circ} \mathrm{C}\right), t_{v 2}$ is the outlet temperature of the heat transfer medium $\left({ }^{\circ} \mathrm{C}\right), t_{v 1}$ is the inlet temperature of the heat transfer medium $\left({ }^{\circ} \mathrm{C}\right)$.

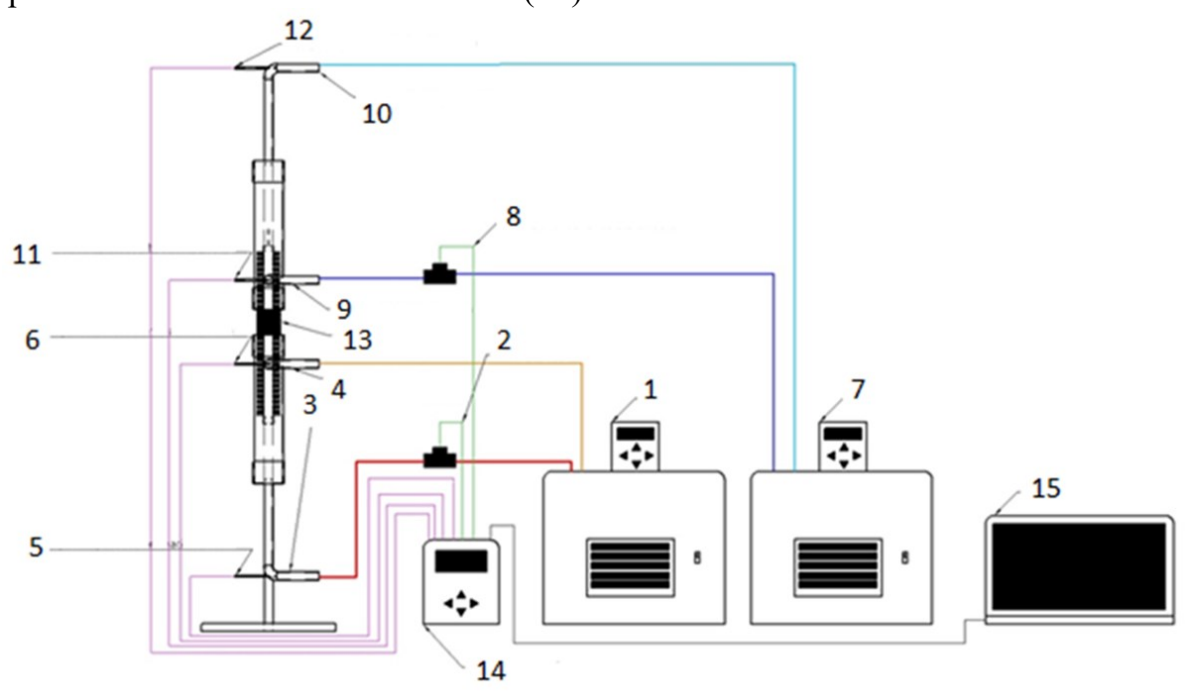

Fig. 5. Scheme of measuring rig 1) hating thermostat, 2) flowmeter, 3) input of heating part, 4) output of heating part, 5) temperature sensor, 6) temperature sensor, 7) cooling thermostat, 8) flowmeter, 9) input of cooling part, 10) output of cooling part, 11) temperature sensor, 12) temperature sensor, 13) insulating part, 14) measuring unit, 15) PC.

\subsection{Analysis of results}

The aim of the experimental measurement was to determine the onset curve and to determine the amount of thermal power transferred by a gravitational heat pipe with an increased heat exchange area and without an increased heat exchange area. 


\subsubsection{Onset curve of heat pipes}

The measurement of the onset curve for gravitational heat pipes is justified in that we can determine exactly at what temperature conditions the heat pipe will start working and whether it works properly. In Figure 6 is the onset curve of a heat pipe without an increased heat exchange area, and in Figure 7 is the onset curve of a heat pipe with an increased heat area.

The determination of the onset curve of the heat pipe on the experimental device was carried out systematically step by step. First, the cooling circuit was started and allowed to stabilize so that the temperature on all sensors was the same as the control temperature of the thermostat of $20^{\circ} \mathrm{C}$. After reaching a constant temperature in the cooling circuit, the heat circuit was started. The initial temperature of the evaporating part of the heat pipe was $20{ }^{\circ} \mathrm{C}$. After the heating started, the temperature of the evaporating part of the heat pipe gradually increased up to the temperature set on the heating thermostat $80^{\circ} \mathrm{C}$. It was observed at what time and at what temperature the temperature in the cooling part of the measuring device will start to rise and how it will change with the change in the evaporating part of the heat pipe.

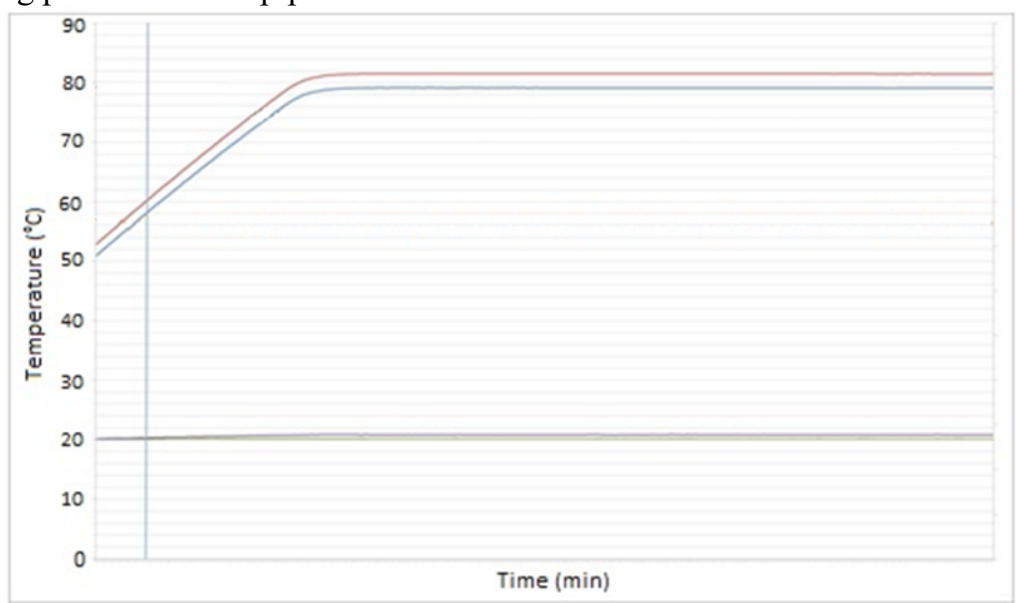

Fig. 6. Start-up curve of a heat pipe without an increased heat exchange area.

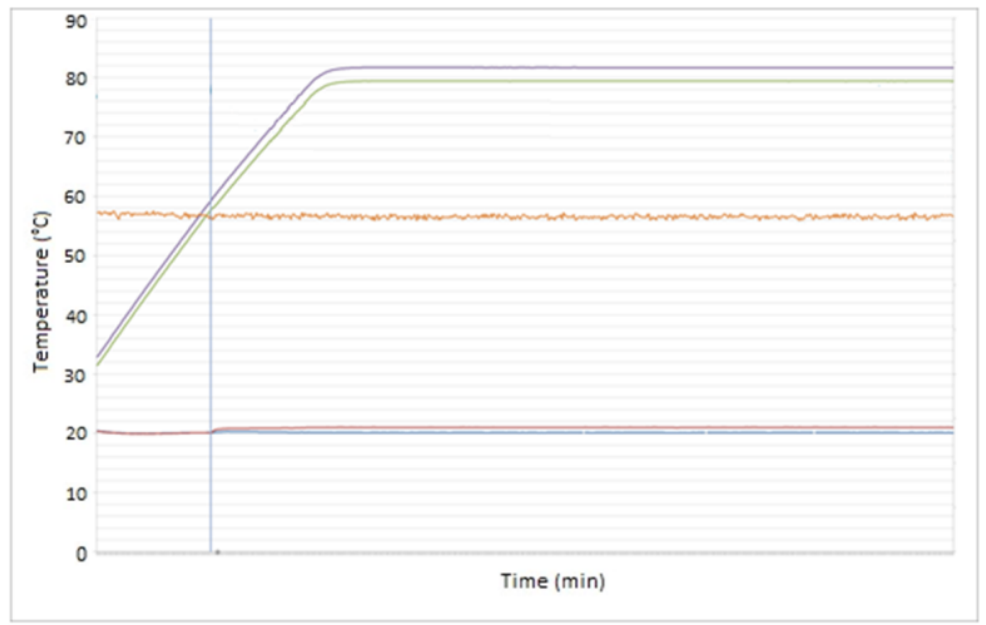

Fig. 7. Start-up curve of a heat pipe with an increased heat area. 
In the case of a gravity heat pipe with an increased heat exchange area, a temperature difference was observed in the cooling part of the system at a heating system temperature of $60.31{ }^{\circ} \mathrm{C}$, which marks the beginning of heat pipe operation and phase transfer of heat transfer medium inside the heat pipe. The observed temperature difference in the cooling system increased until the temperature reached $80^{\circ} \mathrm{C}$ in the evaporator. Then the temperature difference in the cooling system was uniform throughout the operation, which meant that the heat pipe transmitted the heat output constants.

In the case of a gravity heat pipe without an increased heat exchange area, a temperature difference was observed in the cooling part of the system at a heating system temperature of $59.19{ }^{\circ} \mathrm{C}$, indicating the onset of heat pipe operation and phase transfer of the heat transfer medium inside the heat pipe. The observed temperature difference in the cooling system increased until the temperature reached $80^{\circ} \mathrm{C}$ in the evaporator. Then the temperature difference in the cooling system was uniform throughout the operation, which meant that this heat pipe also transmitted the thermal power constants.

\subsubsection{Thermal performance of heat pipes}

Since the detected difference in the onset curve between the gravitational heat pipe with an increased heat exchange surface and the gravitational heat pipe without the increased heat exchange surface is almost negligible, the thermal power of both types of heat pipes could be further measured and compared.

Originally, nine heat pipes were produced. Four without an increased heat exchange area and five with an increased heat exchange area. At the determining the onset curve of the heat pipes, it was found that two of each type were non-functional (manufacturing error) and no thermal performance measurement was performed with these heat pipes. In Figure 8 are measured thermal powers transmitted by the manufactured heat pipes. Heat pipes without an increased heat exchange area are red colour marked and heat pipes with an increased heat transfer area are blue colour marked.

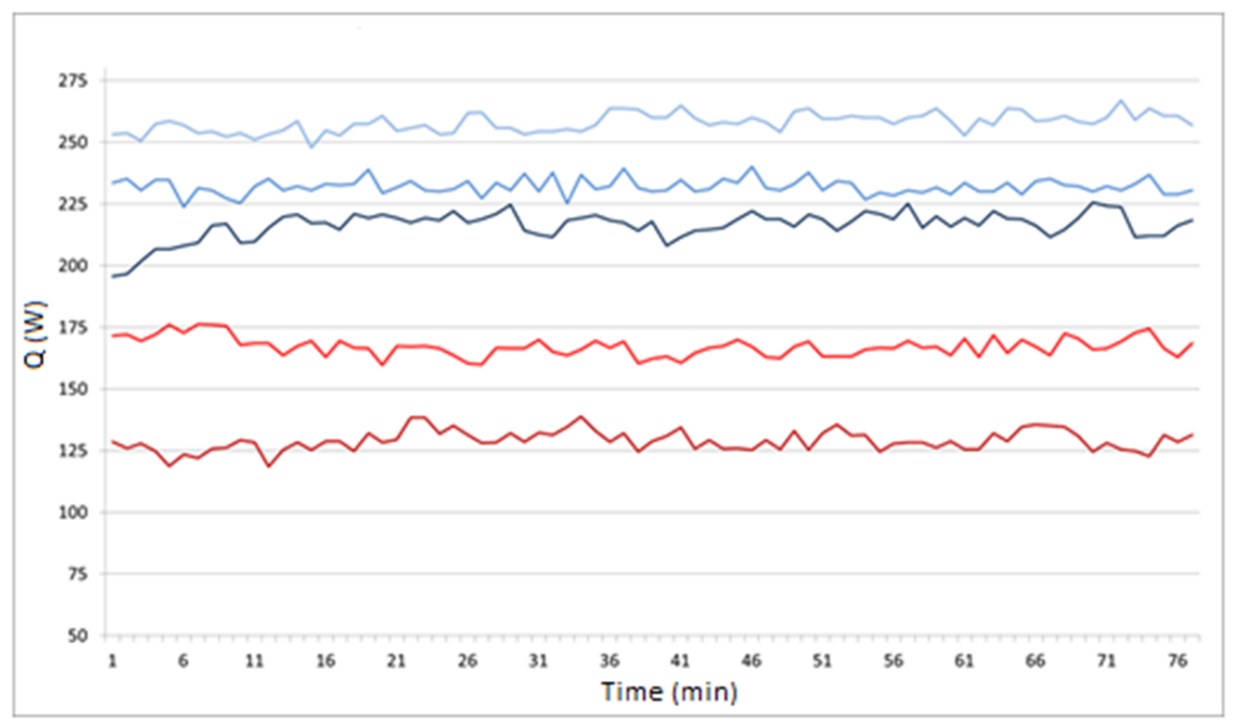

Fig. 8. Thermal performances of gravitational heat pipes.

The average value of the transferred thermal power of the heat pipe without increased heat exchange area is $236 \mathrm{~W}$. The average value of the transferred thermal power of the heat pipe with increased heat exchange area is $150 \mathrm{~W}$. Comparison of the values of 
transferred thermal power showed a significant difference between heat pipes. Gravity heat pipes with an increased heat exchange area were able to transfer more heat output than gravity heat pipes without an increased heat exchange area by an average of $37 \%$.

\section{Design of a heat exchanger for electrical cabinets with power elements}

Based on the positive results obtained from the measurements, it is possible to design a heat exchanger made of heat pipes with an increased heat exchange area for electrical cabinets with power elements. In Figure 9 is an electrical cabinet with power elements which has a free space in the upper part for the location of the heat exchanger. These devices are used, for example, in electric traction vehicles. The dimensions of the internal space for the heat exchanger location are $\mathrm{h} / \mathrm{w} / 1$ 120/240/900 mm.

By a suitable configuration of the heat pipes, it is possible to create a heat exchanger which will have an evaporating part inserted in the inner space of the electrical box and a condensing part in the outdoor space in which the absorbed heat will be dissipated.

In Figure 9 is a design of a heat exchanger with an increased heat transfer surface for dust-free cooling of the electrical cabinet. To increase the effect of heat dissipation from the cabinet, it is possible to dissipate heat in the condensing section by forced convection caused by a fan.

This type of heat exchanger guarantees dust-free operation of power elements in an electrical cabinet with sufficient cooling potential. The design of the size of the heat exchanger can be done according to the amount of heat that needs to be removed. The design can be based on the results obtained from experimental measurements.
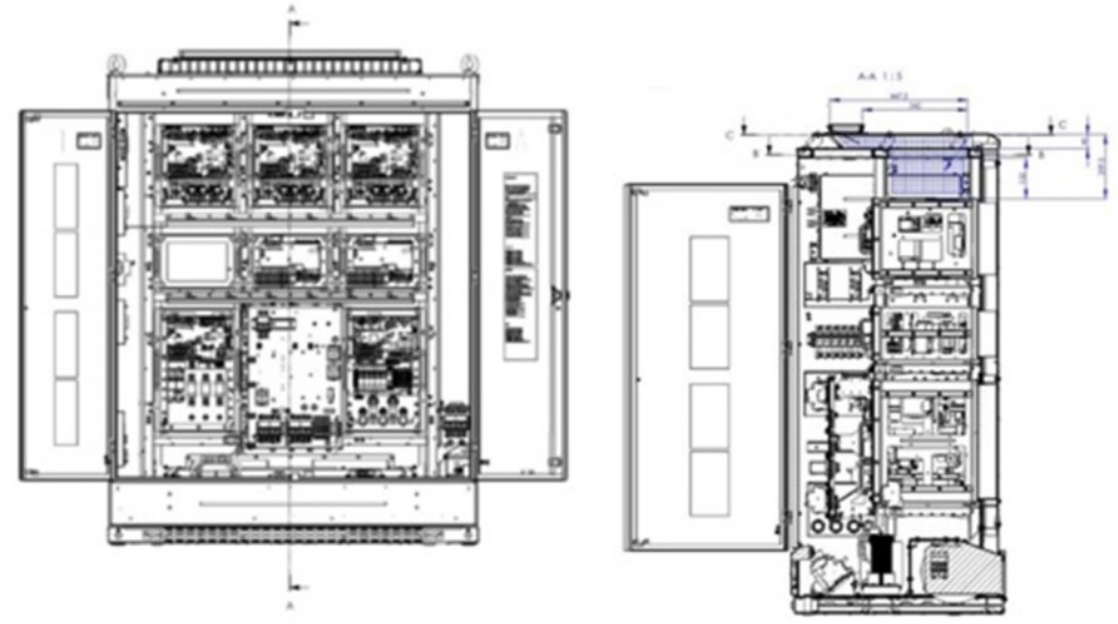

Fig. 9. Electrical cabinet. 


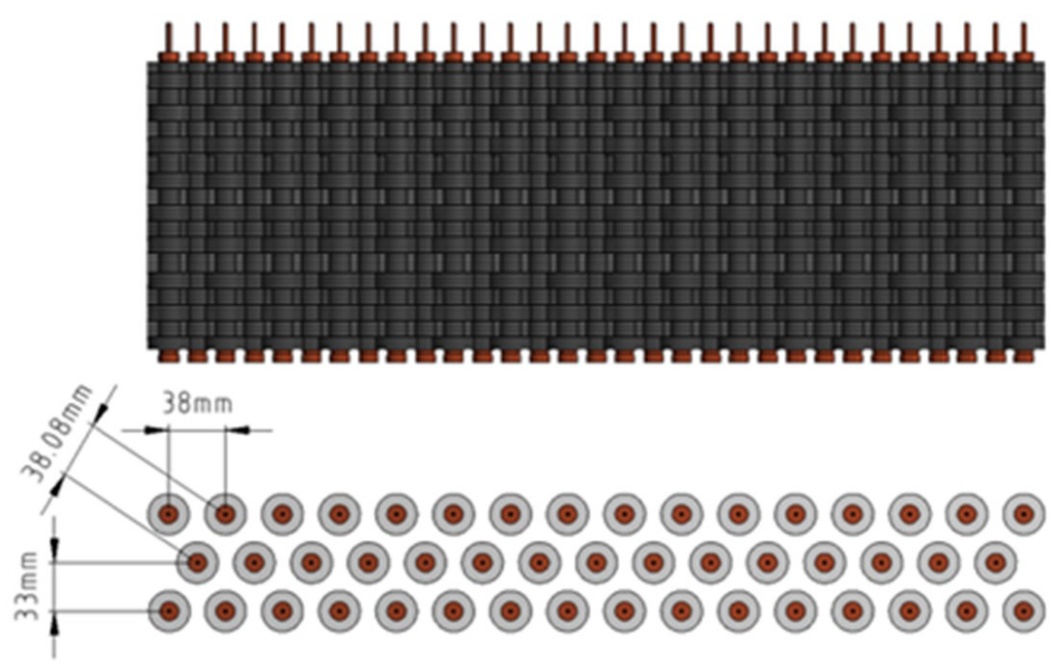

Fig. 10. Heat exchanger design from heat pipes with increased heat transfer surface.

\section{Conclusion}

The aim of the work was to design, experimentally verify the functionality and measure the transmitted thermal power of a heat pipe with an increased heat exchange area, suitable for the design of a heat exchanger for heat removal from the electrical cabinet by a dust-free method. It is clear from the measured results that gravitational heat pipes with an increased heat exchange area are able to transfer more heat power than heat pipes without an increased heat exchange area. Despite the fact that, depending on the appearance of the onset curves, both types of heat pipes functionally seemed to be the same. A gravity heat pipe with an increased heat exchange surface transmitted a higher thermal power by an average of $37 \%$ than a gravity heat pipe without an increased heat exchange surface. A variant of a heat exchanger from heat pipes with an increased heat exchange surface was designed, the theoretical potential of which to dissipate heat from the model electrical cabinet is up to $8 \mathrm{~kW}$. The advantage of this heat exchanger is its operation without any energy costs, maintenance-free operation and dust-free operation of the electrical cabinet space.

This work was founded by projects KEGA 048ŽU-4/2019 and VEGA 1/0738/18.

\section{References}

1. P. G. Peterson, An introduction to heat pipes modelling, testing and applications (2010)

2. D. Reay, P. Kew, R. McGlen, Heat pipes - Theory, design and applications (2014)

3. C. Silverstein, Design and technology of heat pipes for cooling and heat exchangers (2011)

4. R. Nosek, S. Gavlas, R. Lenhard, M. Malcho, V. Sedlak, S. Teie, 11th International Conference of Processes in Isotopes and Molecules, 1917 (2017)

5. A. Kapjor, T. Gressak, J. Huzvar, M. Vantuch, AIP Conference Proceedings 103, 1608 (2014)

6. P. Durcansky, M. Patsch, J. Jandacka, 20th International Scientific Conference on Application of Experimental and Numerical Methods in Fluid Mechanics and Energy (2016) 
7. M. Vantuch, K. Kaduchova, R. Lenhard, 20th International Scientific Conference on Application of Experimental and Numerical Methods in Fluid Mechanics and Energy (2016)

8. M. Holubcik, E. Jachniak, H. Smatanova, AIP Conference Proceedings, 1608, 48 (2014)

9. P. Pilat, M. Patsch, J. Jandacka, Experimental Fluid Mechanics 2011, 25 (2012)

10. N. Kantova, J. Jandacka, M. Holubcik, A. Caja, 36th Meeting of Departments of Fluid Mechanics and Thermodynamics, 1889 (2017)

11. R. Lenhard, K. Kaduchová, Š. Papučík, AIP Conference Proceedings, 1608 (1), 146 (2014)

12. S. Gavlas, P. Ďurčanský, R. Lenhard, J. Jandačka, EPJ Web of Conferences, 92, paper number 02019 (2015)

13. J. Jandacka, M. Holubcik, M. Malcho, R. Nosek, Acta Facultitas Xylologiae Zvolen, 55 (2), 105 (2013)

14. M. Novomestsky, R. Banovcan, A. Kapjor, H. Smatanova, MATEC Web of Conferences, 168 (2018)

15. M. Patsch, A. Caja, 9th International Conference on Experimental Fluid Mechanics (2014) 